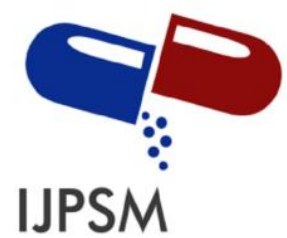

Shivani Khoware et al, Int. Journal of Pharmaceutical Sciences and Medicine (IJPSM),

Vol.6 Issue. 3, March- 2021, pg. 85-109

ISSN: 2519-9889

Impact Factor: $\mathbf{3 . 4 2 6}$

\title{
FORMULATION AND EVALUATION OF SLN BASED TOPICAL GEL OF KETOROLAC TROMETHAMINE
}

\author{
Shivani Khoware*; Amreen Khan; Vimukta Sharma \\ Department of Pharmaceutics: BM College of Pharmaceutical Education and Research, Indore \\ Corresponding author email id: shivanikhoware0@gmail.com \\ Contact no. 9131416594, 9993977274 \\ DOI: 10.47760/ijpsm.2021.v06i03.008
}

\begin{abstract}
Ketorolac tromethamine is frequently non-steroidal anti-inflammatory drug (NSAIDs) with analgesic, anti-inflammatory and antipyretic properties, is also nice in relieving symptoms of osteoarthritis, rheumatoid arthritis, ankylosing spondylitis, acute sciatica and low back pain. Solid lipid nanoparticles (SLNs) are able to be used for the focused on of anti-inflammatory drugs, thus accomplish most significant advantages such as reduction in total dose and prevention of systemic toxicity and unusual side effects. The objective of the present investigation was to prepare \&amp; evaluate solid lipid nanoparticle (SLN) based topical gel of nonsteroidal anti-inflammatory drug (NSAID) ketorolac tromethamine for the cure of arthritis which would attenuate the gastrointestinal related toxicities related with oral administration. SLNs had been prepared by means of low temperature solidification technique and characterize by means of particle measurement, analysis, FTIR spectroscopy, drug entrapment efficiency, SEM, in vitro In vitro release research were performed on Franz diffusion cell the usage of dialysis membrane in phosphate buffer solution of pH 7.4. The FTIR study indicates no predominant interaction of ketorolac tromethamine with different component ingredients and the Scanning Electron Microscope study revealed that the drug is molecularly dispersion into the lipid. The particle measurement determination confirms the particle distribution in the nanoparticle range (27\% volume to 56\% volume). In vitro drug release using the dialysis membrane as of the prepared SLNs is greatly higher than the pure drug. The stability of the formulation shows the stability of the formulation besides changing its performances on storage. Hence formulation of ketorolac tromethamine in SLN, enhances the dissolution price as properly as it will enhance the bioavailability of the drug which ought to the stabilized for the duration of storage.
\end{abstract}

Keywords: Solid Lipid Nanoparticle, Lipophilic Drug, Solidification Method, Franz Diffusion Cell. 


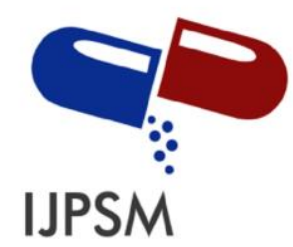

Shivani Khoware et al, Int. Journal of Pharmaceutical Sciences and Medicine (IJPSM), Vol.6 Issue. 3, March- 2021, pg. 85-109

ISSN: 2519-9889

Impact Factor: 3.426

\section{INTRODUCTION}

Ketorolac, an anti-inflammatory agent with analgesic and antipyretic properties, is used to treat osteoarthritis and control acute pain. It is a peripherally acting analgesic. The biological activity of ketorolac tromethamine is associated with the $\mathrm{S}$ - form. Ketorolac tromethamine possesses no sedative or anxiolytic properties. The primary mechanism of action responsible for ketorolac's anti-inflammatory, antipyretic and analgesic effects is the inhibition of prostaglandin synthesis by competitive blocking of the enzyme cyclooxygenase (COX). Ketorolac is a non-selective COX inhibitor. Ketorolac has been assessed to be a relatively higher risk NSAID when compared to aceclofenac, celecoxib, and ibuprofen. This medication is a non-steroidal antiinflammatory drugs. It works by blocking your body's production certain natural substance that cause inflammation. This effect helps to decrease swelling, pain, or fever. The Solid lipid nanoparticles are a new pharmaceutical delivery system or pharmaceutical formulation. Solid lipid nanoparticles are one of the novel potential colloidal carrier system in the range of 100$1000 \mathrm{~nm}$. An alternative material to polymers which is identical to oil in water emulsion for parental nutrition but the liquid lipid of the emulsion has been replaced by a solid liquid. SLNs are sub-micron colloidal carriers ranging from $50-1000 \mathrm{~nm}^{[2][6]}$ They have many advantages such as a good biocompatibility low toxicity and lipophilic drug are better delivered by solid lipid Nano-particles and the system is physically stable. Solid lipid nanoparticles may be a promising sustained release and drug targeting system. Nanoparticles are manufactured from both the synthetic and natural polymer and colloidal particles having range in size between 10 and $1000 \mathrm{~nm}$ are known as nanoparticles ${ }^{[1]}$. Solid lipid nanoparticles are defined as the potential colloidal carrier system in which used to polymers such like lipid, surfactant and other emulsifier's additives. Solid lipid nanoparticles must use for increase the biocompatibility of the drug or reduced to toxicity and target drug delivery system. The solid lipid nanoparticles composed of solid lipid having size ranges between 100-1000 nm and the formulation of solid lipid nanoparticles for drug delivery is depends on their ability to penetrate through several anatomical barrier.

\section{MATERIAL}

Ketorolac tromethamine was purchased for Saurav Chemical Limited (Haryana) India. All chemicals and reagents were of analytical grade (AR). 


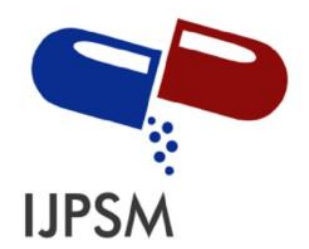

Shivani Khoware et al, Int. Journal of Pharmaceutical Sciences and Medicine (IJPSM), Vol.6 Issue. 3, March- 2021, pg. 85-109

ISSN: 2519-9889

Impact Factor: 3.426

\section{METHODS}

\section{Preformulation studies}

A well designed preformulation study is therefore necessary to fully characterize molecules during the discovery and development processes so that the new drug entities have the appropriate properties, and there is an understanding of the shortcoming that must be overcome by the formulation process.

\section{Solubility Analysis}

Solubility is an essential and extensively studies of pre formulation. Which include selection of suitable solvent, to dissolve the respective drug. The solubility was done by adding the small amount of solute to the fixed volume of solvent, after each addition, the system was vigorously shaken and examined visually for the un-dissolved solute particle.

\section{Melting point}

In the procedure, a small amount of ketorolac tromethamine drug was filled in a capillary tube open both the ends and it was placed along with thermometer in melting point apparatus ( Bio technics India, BTI-34).

\section{pH Value}

$1 \%$ solution was prepared in pure distilled water taken small amount of methanol and $\mathrm{pH}$ of the solution was measured at $25 \pm 1^{\circ} \mathrm{C}$ using by digital $\mathrm{pH}$ meter (Chemi line CL110).

\section{Partition Coefficient}

The partition coefficient study of ketorolac tromethamine was performed using n-octanol as oil phase and water (1:1) as the aqueous phase. The two phases were mixed in equal quantities (50 $\mathrm{ml}$ ) by adding 50mg of drug in a separating funnel and was saturated with each other at room temperature for 24 hour. The saturated phase were separated by centrifugation. 


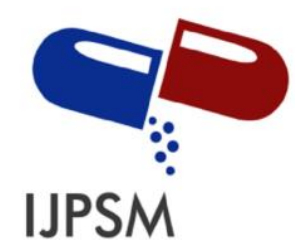

Shivani Khoware et al, Int. Journal of Pharmaceutical Sciences and Medicine (IJPSM),

Vol.6 Issue. 3, March- 2021, pg. 85-109

ISSN: 2519-9889

Impact Factor: 3.426

The two phases were separated and then analyzed for respective drug contents. The partition coefficient measured by the given formula.

$$
K\left(\frac{0}{w}\right)=\frac{\text { conc. of the drug in oil phase }}{\text { conc. of the drug in an aquouse phase }}
$$

Where,

$\mathrm{K}$ is a partition coefficient.

\section{Spectrophotometric Analysis}

\section{Calibration Curve of Ketorolac Tromethamine with 7.4 pH phosphate buffer}

Weight 100mg ketorolac tromethamine and dissolve $100 \mathrm{ml}$ of phosphate buffer solution $\mathrm{pH} 7.4$, make $1000 \mu \mathrm{g} / \mathrm{ml}$ solution. Then take $1 \mathrm{ml}$ of above solution and volume make up 10ml with buffer solution $(100 \mu / \mathrm{ml})$. Take $0.5,1,1.5,2,2.5$ and $3 \mathrm{ml}$ of above solution, make up the volume of $10 \mathrm{ml}$ individually dilutions, the concentrations are 5, 10, 15, 20, 25 and $30 \mu \mathrm{g} / \mathrm{ml}$. Plot the calibration curve of these different concentration's dilution by uv visible spectrophotometry at the range of $200-400 \mathrm{~nm}$.

\section{FTIR Spectrometry}

The IR analysis of the sample was carried out for qualitative compound identification. In ATR (Attenuated Total Reflectance), the solid material is placed onto the small crystal area. In this instrument IRAffinity-1, diamond being the preferred choice for most applications because of its robustness and durability. After solid has been placed on the crystal area, the pressure arm is positioned over the crystal/sample area. Force is applied to the sample, pushing it onto the diamond surface. Transmittance was measured from wave number $4000 \mathrm{~cm}^{-1}$ to $400 \mathrm{~cm}^{-1}$. 


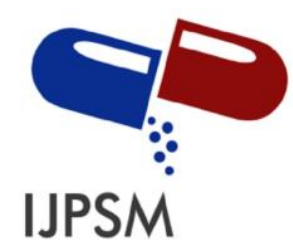

Shivani Khoware et al, Int. Journal of Pharmaceutical Sciences and Medicine (IJPSM),

Vol.6 Issue. 3, March- 2021, pg. 85-109

ISSN: 2519-9889

Impact Factor: 3.426

\section{Preparation of Ketorolac Tromethamine SLN Dispersion}

Solid lipid loaded ketorolac tromethamine drug was prepare using melt emulsification and low temperature solidification method. Ketorolac tromethamine was dissolved in methanol and mixed with the acetone solution or containing steric acid (Lipid). The mixtures ware sonicated for 15 minutes, then added drop wise to tween 20 (surfactant) solution, the mixture was stirred at $3000 \mathrm{rpm}$ for $30 \mathrm{~min}$ at $70^{\circ} \mathrm{C}$ temperature. The mixed solution was transferred to ice water bath and stirring for 4 hour at $3000 \mathrm{rpm}$. Different formulation of drug loaded SLN (SLN1, SLN2,SLN3,SLN4, SLN5 and SLN6) were prepared by varying concentration of steric acid and surfactant.

Table-1 Composition of Different Solid Lipid Nanoparticles.

\begin{tabular}{|l|l|l|l|}
\hline Formulation & Drug $(\mathbf{m g})$ & Stearic acid $(\mathbf{m g})$ & Tween 20 (\%) \\
\hline SLN-1 & 100 & 1000 & 2.0 \\
\hline SLN-2 & 100 & 1250 & 2.0 \\
\hline SLN-3 & 100 & 1500 & 2.0 \\
\hline SLN-4 & 100 & 1000 & 2.5 \\
\hline SLN-5 & 100 & 1250 & 2.5 \\
\hline SLN-6 & 100 & 1500 & 2.5 \\
\hline
\end{tabular}




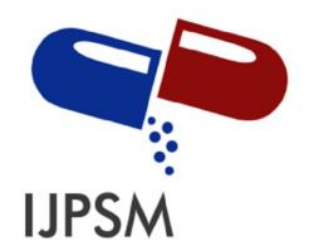

Shivani Khoware et al, Int. Journal of Pharmaceutical Sciences and Medicine (IJPSM),

Vol.6 Issue. 3, March- 2021, pg. 85-109

ISSN: 2519-9889

Impact Factor: $\mathbf{3 . 4 2 6}$

\section{Characterization of Ketorolac Tromethamine loaded SLN dispersion}

\section{Drug Entrapment Efficiency(EE)}

The entrapment efficiency of SLN loaded ketorolac tromethmine was calculate by using $0.1 \mathrm{ml}$ of SLN dissolve in the dispersion medium and the solution was centrifuge at $1200 \mathrm{rpm}$. The supernatant fluid was collected and passed through a membrane filter. The quantity of drug in the solution was measured by UV spectroscopy at $328 \mathrm{~nm}$.

$$
\% E E=\frac{\mathrm{W} 1 \text { initial drug }-\mathrm{W} 2 \text { free drug }}{\mathrm{W} 1 \text { initial drug }} \times 100
$$

Where EE is entrapment efficiency, W1 stands for the mass of ketorolac tromethamine added to the formulation and W2 is the analyzed weight of drug in the supernatant layer.

\section{Zeta Potential \& Particle Size}

Zeta potential is an indication of the stability of the solid lipid nanoparticles. For a stable solid lipid nanoparticles stabilized only by electrostatic repulsion, minimum zeta potential of $\pm 30 \mathrm{mv}$ is required where as in case of a combined electrostatic and steric stabilizer, a zeta potential of $\pm 24 \mathrm{mv}$ would be sufficient. For zeta potential determination samples of formulations was diluted with water and placed in the electrophoretic cell. For each sample was measured 3 times at $25^{\circ} \mathrm{C}$ and average values was employed for measuring the response. The mean particle size and the width of particle size distribution called Polydispersity Index are determined by Photon Correlation Spectroscopy (PCS). Particle size and polydispersity index (PI) govern the saturated solubility dissolution velocity and biological performance. The prepared solid lipid nanoparticles of $100 \mu \mathrm{l}$ was diluted to $5 \mathrm{ml}$ with distilled water and diluted dispersion was measured using Malvern zetasizer.

\section{Scanning Electron Microscopy}

Solid lipid nanoparticle was carried out by the Scanning Electron Microscope. The morphological characterization of solid lipid nanoparticles was determine by the SEM. Taken 1 gm or one drop of SLN and added in $1 \times 1 \mathrm{~cm}$ of carbon tape then put the scanning mould in inert the JEOL- JSM-5600 scanning electron Microscope system. On the specimen chamber and on the evacuation system (EVC), and the image obtained after 10 minute and investigated at $20 \mathrm{kV}$. 


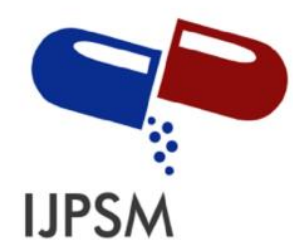

Shivani Khoware et al, Int. Journal of Pharmaceutical Sciences and Medicine (IJPSM), Vol.6 Issue. 3, March- 2021, pg. 85-109

ISSN: 2519-9889

Impact Factor: 3.426

\section{FTIR}

IR spectra of pure drug ketorolac thromethamine with steric acid was obtained. IR spectroscopic studies was conducted to determine possible interaction between chemical bonds of drug and excipients. The samples was scanned in the region between 4000 . and $400 \mathrm{~cm}^{-1}$.

\section{FORMULATION OF SLN LOADED GEL OF KETOROLAC TROMETHAMINE}

SLN loaded gel was prepared by using required quantity of carbpol 934 is gelling agent. In this method required sufficient amount of carbpol 934 was weighed accurately and dissolve in small volume of distilled water to prepare aqueous dispersion and dispersed carbpol was allowed to hydrate for 3-5 hour. Glycerin (10\% w/w) used as humectants was added subsequently to the aqueous dispersion equivalent to $10 \%$ of ketorolac tromethamine was incorporated in it. Triethanolamine ( viscocity modifier), was added to the carbpol dispersion using stirrer at 1200 rpm. Stirring was continued till the carbpol get dispersed. Then the formulated gel was allowed to stand overnight for the removal of entrapped air. Different formulation of gel ( F1, F2, F3, F4, F5 and F6 ) using different batches of SLN were prepared. Then was gel allowed to further investigation such as physical appearance, $\mathrm{pH}$, viscocity, spreadability and in vitro drug release.

Table-02 Composition Of SLN Gel Formulation

\begin{tabular}{|l|l|}
\hline Ingredients & Composition $(\% \mathbf{w} / \mathbf{w})$ \\
\hline Carbpol 934 & 1 \\
\hline SLN loased drug to 1\% of ketorolac & 1 \\
\hline Glycerin & 10 \\
\hline Triethanolamine & q.s \\
\hline Distilled water & q.s \\
\hline
\end{tabular}




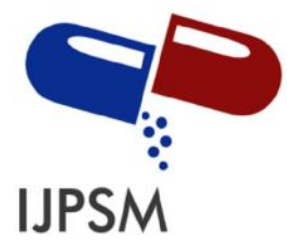

Shivani Khoware et al, Int. Journal of Pharmaceutical Sciences and Medicine (IJPSM), Vol.6 Issue. 3, March- 2021, pg. 85-109

ISSN: 2519-9889

Impact Factor: 3.426

\section{EVALUATION OF KETOROLAC TROMETHAMINE LOADED GEL}

\section{Physical Appearance}

Physical appearance such as color and appearance was observed.

\section{Measurement of pH}

$1 \mathrm{gm}$ of SLN loaded gel was taken and dissolved in $100 \mathrm{ml}$ of distilled water and kept in two hours. After 2 hour checked $\mathrm{pH}$ value for $\mathrm{pH}$ meter.

\section{Viscosity}

Viscosity of the formulated gels were determined using a Brookfield Viscometer using spindle type 63.

\section{Spreadability}

It indicates the extent of area to which gel readily spreads on application to skin or affected part. The therapeutic potency of a formulation also depends upon its spreading value. Spreadability is expressed in terms of time in seconds taken by two slides to slip off from gel which is placed in between the slides under the direction of certain load. Lesser the time taken for the separation of two slides, better the spreadability. It is calculated by using the formula:

$$
S=M \times L / T
$$

where,

$\mathrm{M}=$ wt. tied to upper slide

$\mathrm{L}=$ length of glass slides

$\mathrm{T}=$ time taken to separate the slides 


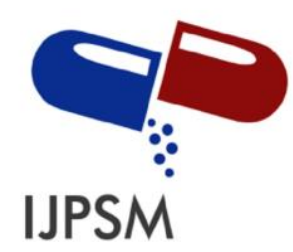

Shivani Khoware et al, Int. Journal of Pharmaceutical Sciences and Medicine (IJPSM), Vol.6 Issue. 3, March- 2021, pg. 85-109

ISSN: 2519-9889

Impact Factor: 3.426

\section{In vitro drug release study}

The in vitro drug release studies were performed using modified franz diffusion cell to evaluated the amount of ketorolac tromethamine from each formulation. These cell consist of two cells one is the donor compartment, and one is the accepter compartment, dialysis membrane 70 , magnetic stirring, thermostatic water bath and sampling device.

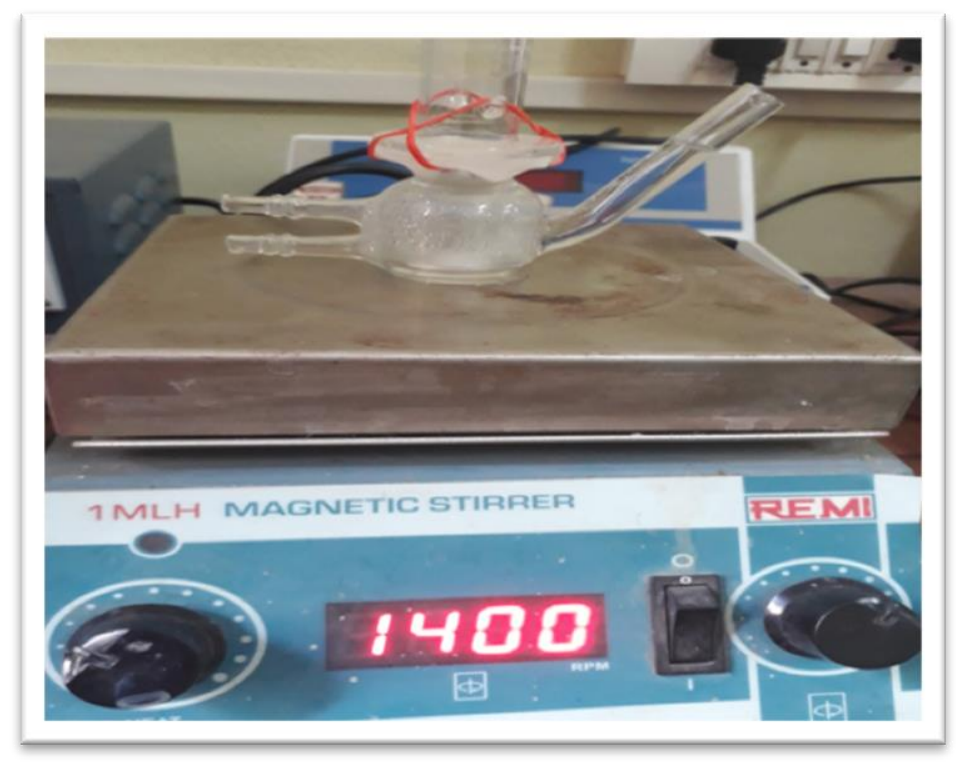

Figure-1 Franz Diffusion Cell

Dialysis membrane 70 having pore size $2.4 \mathrm{~nm}$ and molecular weight cut-off between 12,000 14,000 was used to mounted on the franz diffusion cells. The surface area of the release membrane was $3.15 \mathrm{~cm}^{2}$. The receptor medium was approximately $50 \mathrm{ml}$ and composed of phosphate buffer, $\mathrm{pH}$ 7.4. and the stirrer the magnetic bar at 700 to $1400 \mathrm{rpm}$ avoid different concentrations within the acceptor medium and to minimize stagnant layer. SLN based gel (equivalent to $30 \mathrm{mg}$ of drug) were placed in the donor compartment. During the processed, the solution in receptor side was maintained at $37^{\circ} \mathrm{C} \pm 0.5^{\circ} \mathrm{C}$, after a certain time interval, $2 \mathrm{ml}$ of the sample was withdraw at different time interval from receiver compartment through side tube and volumes of freshly prepared receptor medium were added. 


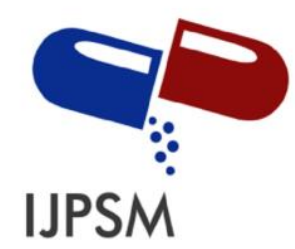

Shivani Khoware et al, Int. Journal of Pharmaceutical Sciences and Medicine (IJPSM), Vol.6 Issue. 3, March- 2021, pg. 85-109

ISSN: 2519-9889

Impact Factor: 3.426

The samples were analyzed by UV- Visible spectrophotometer at $328 \mathrm{~nm}$. For each formulation, the released studies were performed in triplicate and mean was taken. Franz cell glass structure represented in given figure1.

\section{FTIR spectrophotometry}

IR spectra of pure drug ketorolac tromethamine with carbopol 934 was obtained. IR spectroscopic studies was conducted to determine possible interaction between chemical bonds of drug and excipients. The samples was scanned in the region between $4000-400 \mathrm{~cm}^{-1}$

\section{Stability Study}

The SLNs loaded gel of the formulations after 1 month was observed. The formulations at $40^{\circ} \mathrm{c}$ remained stable. The stability studies of formulation F1, F2 and F3 had been performed. The stability studies observed in physical appearance and compatibility formulations. We were stored each formulation at room temperature and high temperature for 1 month.

\section{RESULT \& DISCUSSION}

\section{Organoleptic properties}

The ketorolac tromethamine drug was studies for their organoleptic properties like colour, odour, taste, crystallinity and observation was recorded in table 02.

Table 02: Organoleptic Properties of Drug.

\begin{tabular}{|l|l|}
\hline Parameter & Ketorolac tromethamine \\
\hline Colour and Physical appearance & Off -white crystalline powder \\
\hline Odor & Odorless \\
\hline Taste & Tasteless \\
\hline
\end{tabular}




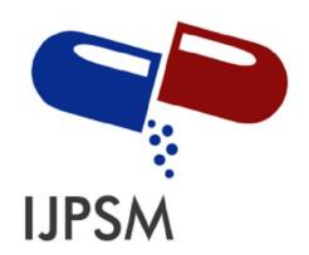

Shivani Khoware et al, Int. Journal of Pharmaceutical Sciences and Medicine (IJPSM),

Vol.6 Issue. 3, March- 2021, pg. 85-109

ISSN: 2519-9889

Impact Factor: 3.426

\section{Melting point}

The melting point of the drug was found to be $165^{\circ} \mathrm{C}$, which was in the reported range indicating that the drug sample was pure.

Table 03: Melting point of ketorolac tromethamine

\begin{tabular}{|l|l|l|}
\hline Drug & Observed & Reference \\
\hline $\begin{array}{l}\text { Ketorolac } \\
\text { thromethamine }\end{array}$ & $165 \pm 2^{\circ} \mathrm{C}$ & $165-167^{\circ} \mathrm{C}$ \\
\hline
\end{tabular}

\section{pH Measurement}

The $\mathrm{pH}$ value of the drug was found to be 6.4 , which was in the reported range indicating that the drug sample was pure

Table 04: pH value of ketorolac tromethamine

\begin{tabular}{|l|l|l|}
\hline Drug & Observed & Reference \\
\hline $\begin{array}{l}\text { Ketorolac } \\
\text { thromethamine }\end{array}$ & 6.4 & 5.7 to 6.7 \\
\hline
\end{tabular}

\section{Partition Coefficient}

Partition coefficient of ketorolac tromethamine was found to be 7.33 (0ctanol/phosphate buffer $7.4 \mathrm{pH}$ ), which showed that ketorolac tromethamine. Possess sufficient lipophillicity as well as hydrophillicity. Which are necessary for its permeation through the skin.

Table 05: Partition coefficient value of Ketorolac Tromethamine

\begin{tabular}{|l|l|l|}
\hline Drug & Observed & Reference \\
\hline $\begin{array}{l}\text { ketorolac } \\
\text { tromethamine }\end{array}$ & 7.33 & $5.68-8.27$ \\
\hline
\end{tabular}






Shivani Khoware et al, Int. Journal of Pharmaceutical Sciences and Medicine (IJPSM), Vol.6 Issue. 3, March- 2021, pg. 85-109

ISSN: 2519-9889

Impact Factor: 3.426

\section{Solubility Analysis}

Ketorolac tromethamine was freely soluble in water and methanol. That the slightly soluble in alcohol, in dehydrated alcohol. Ketorolac tromethamine was insoluble in acetone and toluence.

Table-06 The solubility analysis of ketorolac tromethamine

\begin{tabular}{|l|l|}
\hline Solvents & Result \\
\hline Methanol & $+++($ freely soluble $)$ \\
\hline Distilled water & $+++($ freely soluble $)$ \\
\hline Alcohol & $+($ slightly soluble $)$ \\
\hline Phosphate buffer $(7.4 \mathrm{pH})$ & $++($ soluble $)$ \\
\hline Acetone & $-($ insoluble $)$ \\
\hline
\end{tabular}




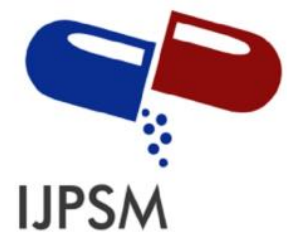

Shivani Khoware et al, Int. Journal of Pharmaceutical Sciences and Medicine (IJPSM), Vol.6 Issue. 3, March- 2021, pg. 85-109

ISSN: 2519-9889

Impact Factor: 3.426

\section{UV spectrum analysis}

UV spectroscopic analysis for the ketorolac tromethamine drug sample was performed and the maximum absorption is found the $\lambda$ max was observed at $328 \mathrm{~nm}$.

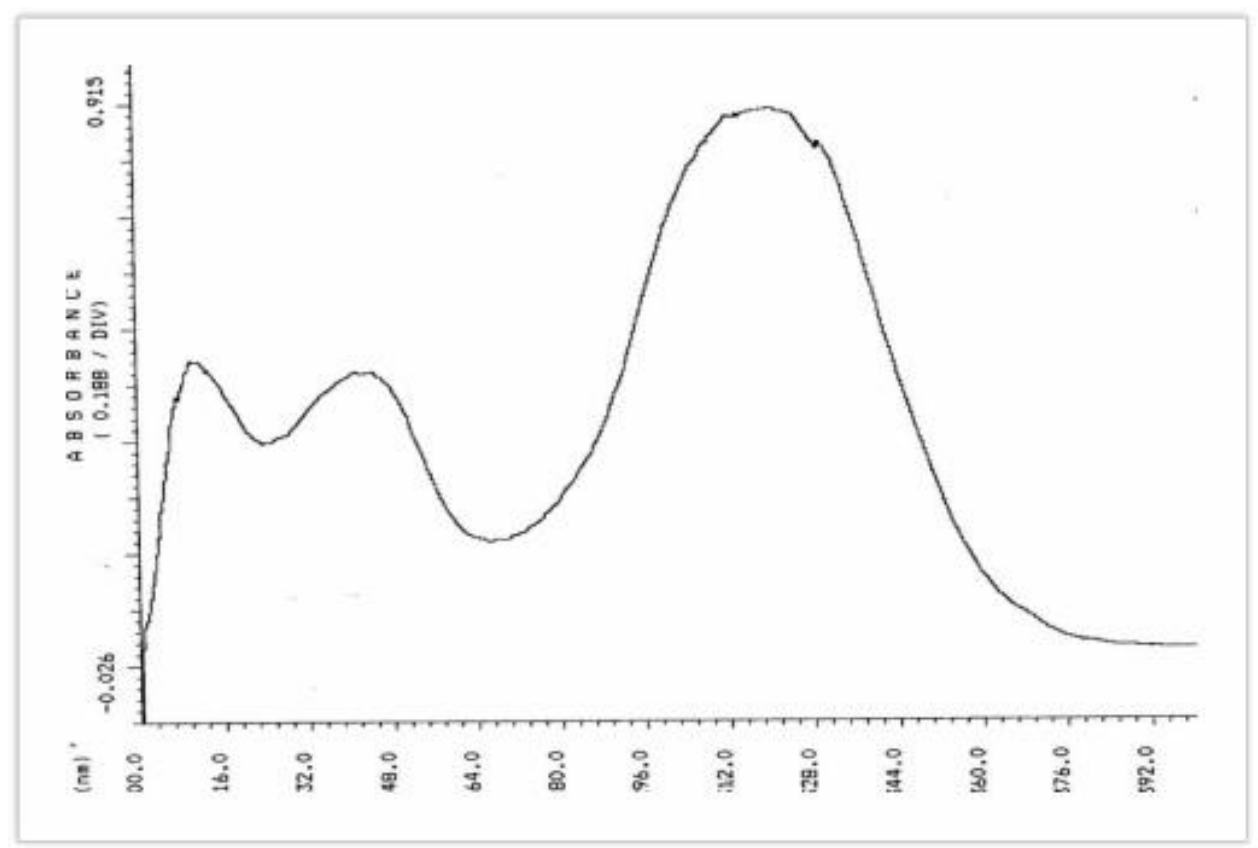

Fig.2 UV spectrum of Pure Ketorolac tromethamine drug 


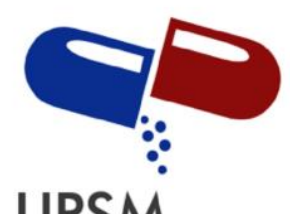

Shivani Khoware et al, Int. Journal of Pharmaceutical Sciences and Medicine (IJPSM),

Vol.6 Issue. 3, March- 2021, pg. 85-109

ISSN: 2519-9889

Impact Factor: 3.426

\section{Calibration curve of KT drug with $7.4 \mathrm{pH}$ phosphate buffer}

The calibration curve of drug obeyed Beer Lambert's law in the concentration range of 0-30 $\mu \mathrm{g} / \mathrm{ml}\left(\mathrm{R}^{2}=0.995\right)$ and result shown in figure 3 .

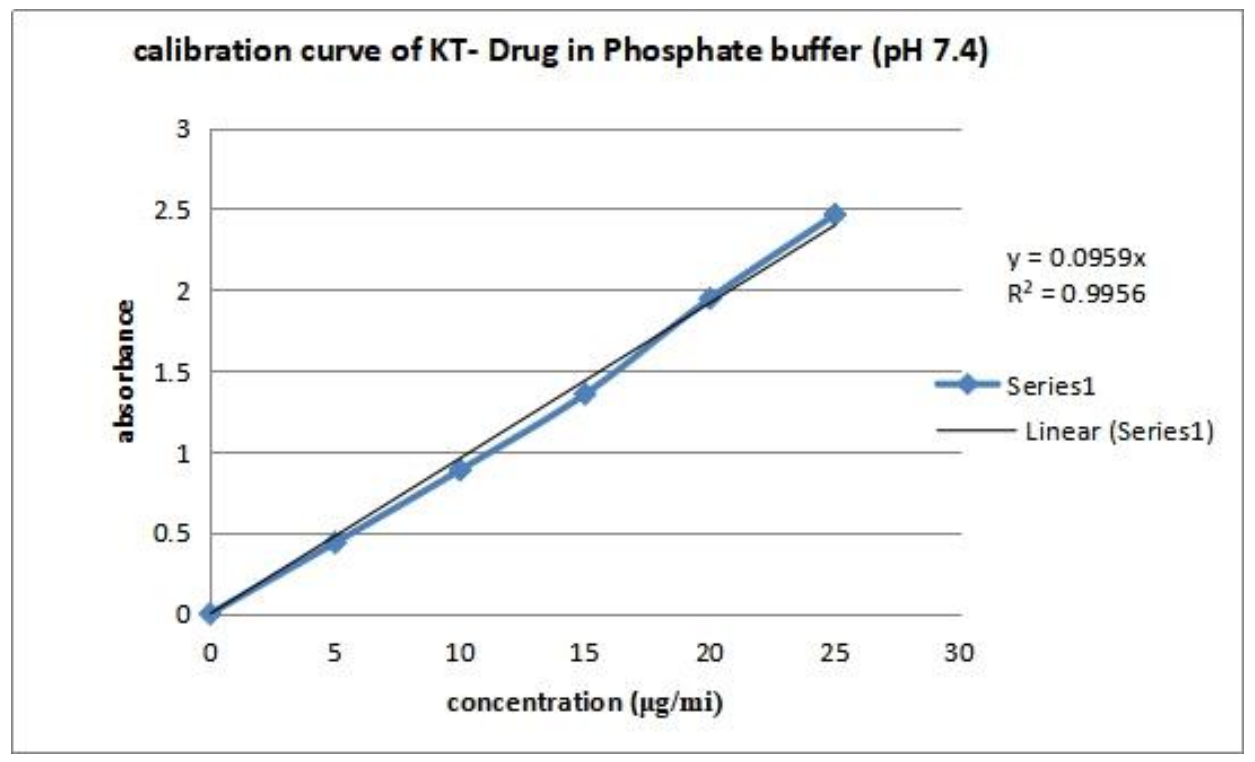

Fig. 4 Calibration Curve of KT Drug in Phosphate Buffer 7.4 pH

\section{Compatibility study FTIR spectrometry}

FTIR spectroscopy of physical mixture of ketorolac tromethamine and physical mixture of drug with polymers were compared. The IR spectrum of drug sample has shown corresponding peak at $3300 \mathrm{~cm}^{-1}$ (O-H stretching- strong broad of- carboxylic group) and $850 \mathrm{~cm}^{-1}$ (C-Cl stretching Strong broad of Helo compound). 


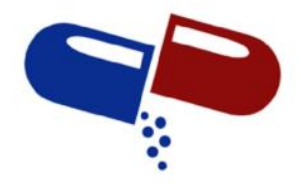

IJPSM

Shivani Khoware et al, Int. Journal of Pharmaceutical Sciences and Medicine (IJPSM), Vol.6 Issue. 3, March- 2021, pg. 85-109

ISSN: 2519-9889

Impact Factor: $\mathbf{3 . 4 2 6}$

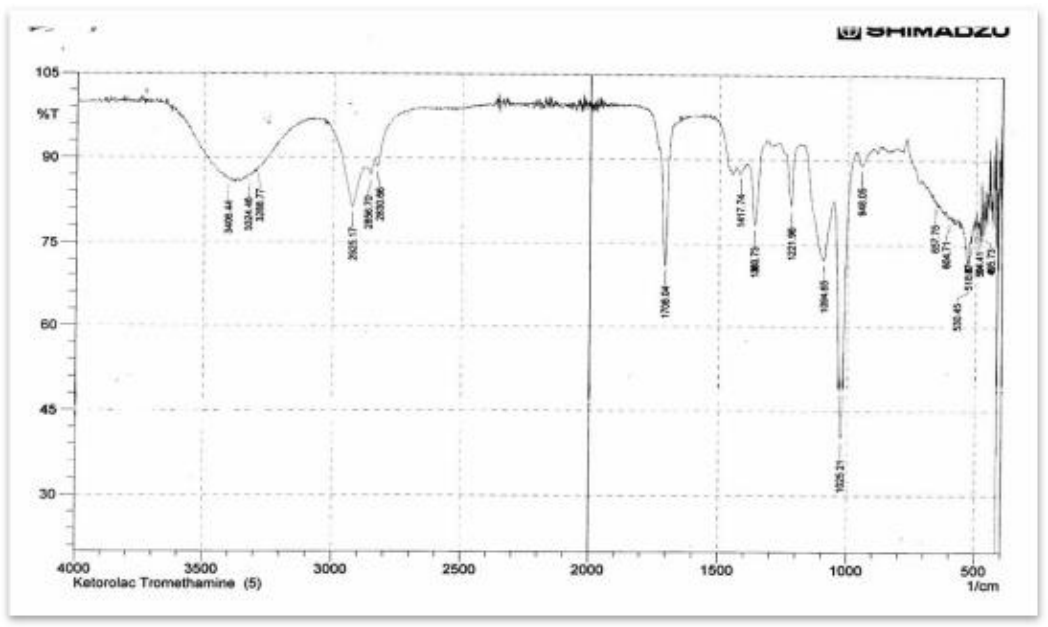

Fig. 5 FTIR oF Pure Ketorolac Tromethamine Drug

The physical mixture shows peak at 2824.87, 704.05. Thus it concluded that the physical mixture of the drug ketorolac tromethamine does not show any major interaction with formulation components like lipid. Thus result shown in figure 06.



Fig. 6 FTIR spectra of physical mixture of KT drug with stearic acid. 


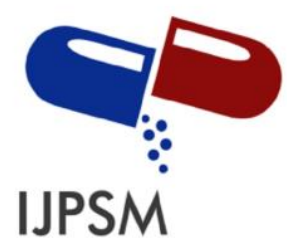

Shivani Khoware et al, Int. Journal of Pharmaceutical Sciences and Medicine (IJPSM),

Vol.6 Issue. 3, March- 2021, pg. 85-109

ISSN: 2519-9889

Impact Factor: 3.426

\section{Evaluation of SLN loaded Gel of Ketorolac tromethamine}

Physical evaluations of SLN loaded gel was shows off white color and translucent appearance.

Table 07 pH, Viscosity, Spreadability

\begin{tabular}{|l|l|c|l|}
\hline Formulation code & pH & Viscosity (cps) & $\begin{array}{l}\text { Spreadability (gm- } \\
\text { cm/sec) }\end{array}$ \\
\hline F1 & 6.7 & 2245.12 & 3.43 \\
\hline F2 & 6.4 & 2567.34 & 3.52 \\
\hline F3 & 6.8 & 2641.23 & 3.62 \\
\hline F4 & 5.9 & 3033.67 & 3.59 \\
\hline F5 & 6.6 & 3098.19 & 3.60 \\
\hline F6 & 7.1 & 3112.23 & 3.64 \\
\hline
\end{tabular}

\section{Percent Drug Entrapment Efficiency}

The SLN was prepared by different proportion of drug, lipid, surfactant. The entrapment efficiency of SLN loaded ketorolac tromethamine increase the concentration of stearic acid and tween 20. The percent drug entrapment efficiency found between 83.55 to $96.00 \%$.

The F6 and F4 given good efficiency (95.67\% and $94.63 \%)$ as the lipid concentration was increased, while F1 and F2 (85.64\% and $89.3 \%)$ was lowest entrapment and decrease the concentration of lipid. 


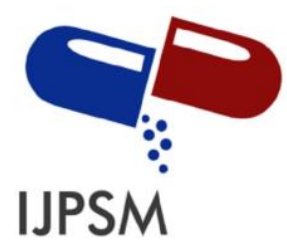

Shivani Khoware et al, Int. Journal of Pharmaceutical Sciences and Medicine (IJPSM), Vol.6 Issue. 3, March- 2021, pg. 85-109

ISSN: 2519-9889

Impact Factor: 3.426

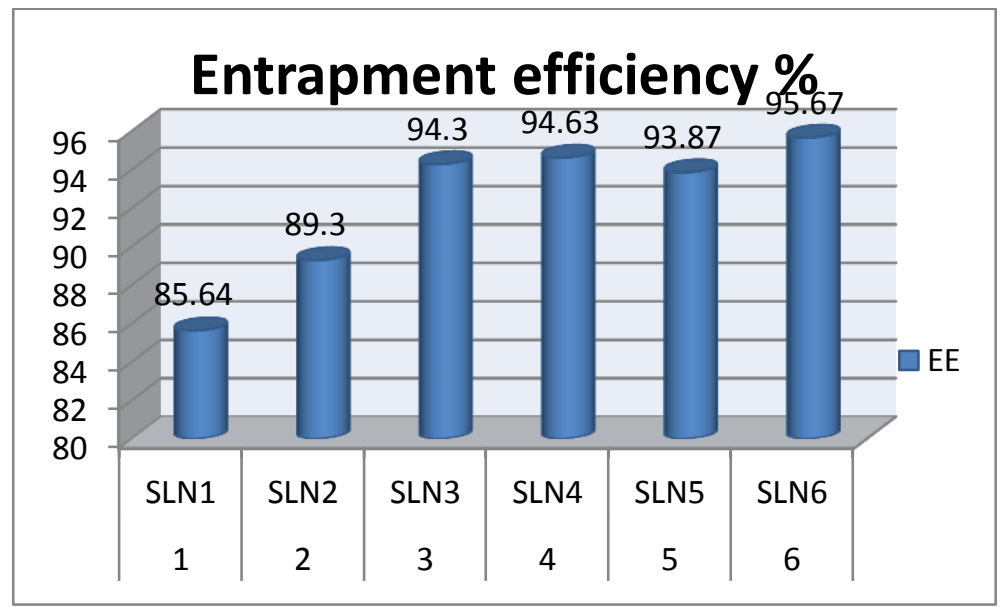

Fig. 07 percent entrapment efficiency

\section{Scanning Electron Microscopy}

The surface analysis of solid lipid nanoparticles were carried out by the scanning electron microscopy. Images ware obtained after SEM and shown in figures, SLN1, SLN3 and SLN6. SLN1 have quit a rough surface, SLN3 was almost dendritcs in shape. SLN1 and SLN3 have a smaller size as compare to SLN6 because higher concentration of tween 20 in SLN1 and SLN3. SLN6 have dendritic - shape and fine smooth surface.

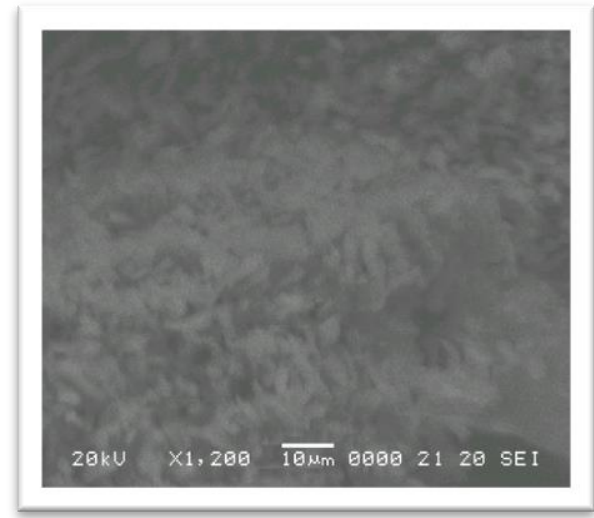

Fig.08 SLN1 


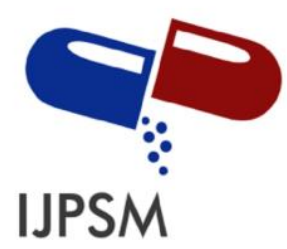

Shivani Khoware et al, Int. Journal of Pharmaceutical Sciences and Medicine (IJPSM), Vol.6 Issue. 3, March- 2021, pg. 85-109

ISSN: 2519-9889

Impact Factor: 3.426

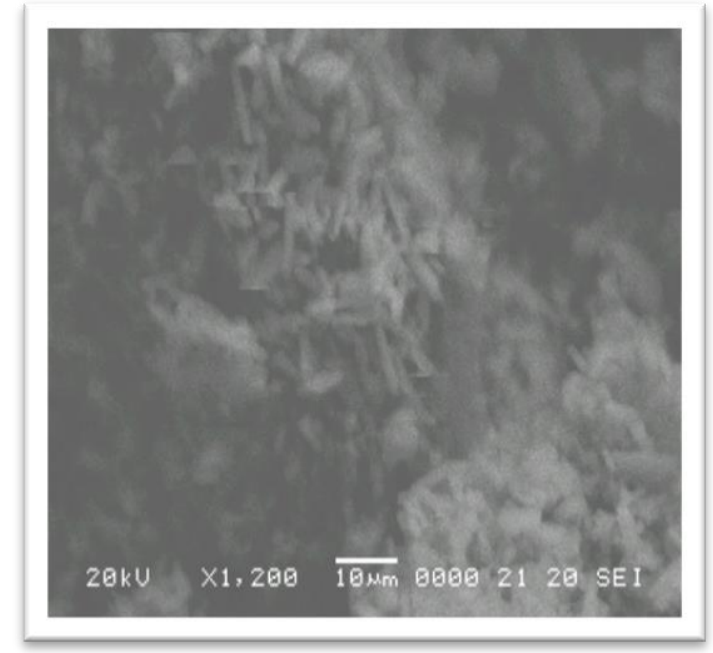

Fig. 09 SLN 3

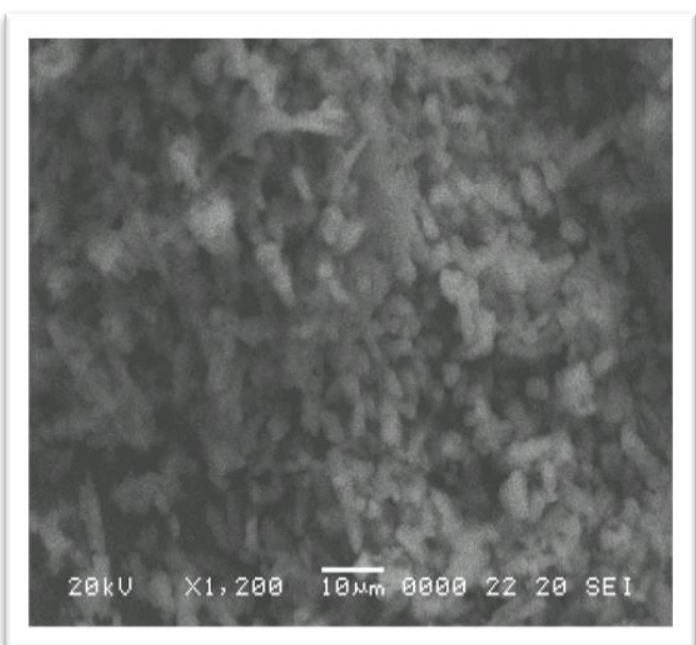

Fig. 10 SLN 6

\section{Zeta Potential \& Particle Size Distribution}

The zeta potential of the SLN1, SLN3 and SLN6 were found to be negative which may be due to the presence of terminal carboxylic groups. High potential values should be achieved to ensure a high-energy barrier and favour a good stability of SLN6.

\section{Particle Size Distribution}

Particle size distribution of SLN1, SLN3 and SLN6 were obtained result shown in figure and table. It was observed particle size distribution of SLN6 was $96.50 \mathrm{~nm}$ at $96.8 \%$ intensity. 


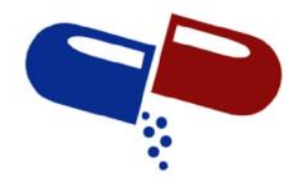

IJPSM

Shivani Khoware et al, Int. Journal of Pharmaceutical Sciences and Medicine (IJPSM), Vol.6 Issue. 3, March- 2021, pg. 85-109

ISSN: 2519-9889

Impact Factor: 3.426

Results

Zeta Potential $(\mathrm{mV}):-24.3$

Zeta Deviation $(\mathrm{mV}): 3.11$

Conductivity $(\mathrm{mS} / \mathrm{cm}): 0.289$

Result quality :

Peak 1: $\quad-24.3$

Peak 2: 0.00

Peak 3: 0.00

Mean (mV)

Area $(\%)$

100.0

0.0

0.0

eta Potential Distribution

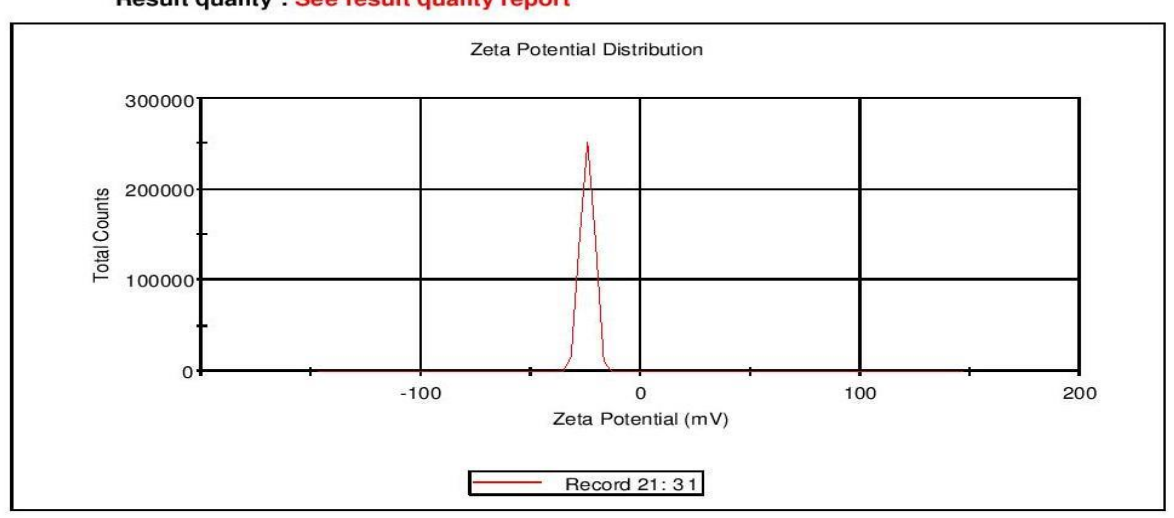

Record 21: 31

Fig. 11 zeta potential of SLN 6

Results

$\begin{array}{rlllll} & & \text { Size (r.nm): } & \text { \% Intensity } & \text { Width (r.nm): } \\ \text { Z-Average (r.nm): } 79.39 & \text { Peak 1: } & 96.50 & 96.8 & 49.36 \\ \text { Pdl: } 0.362 & \text { Peak 2: } & 2684 & 1.7 & 164.8 \\ \text { Intercept: } 0.906 & \text { Peak 3: } & 12.51 & 1.5 & 2.637 \\ \text { Result quality: Good } & & & \end{array}$

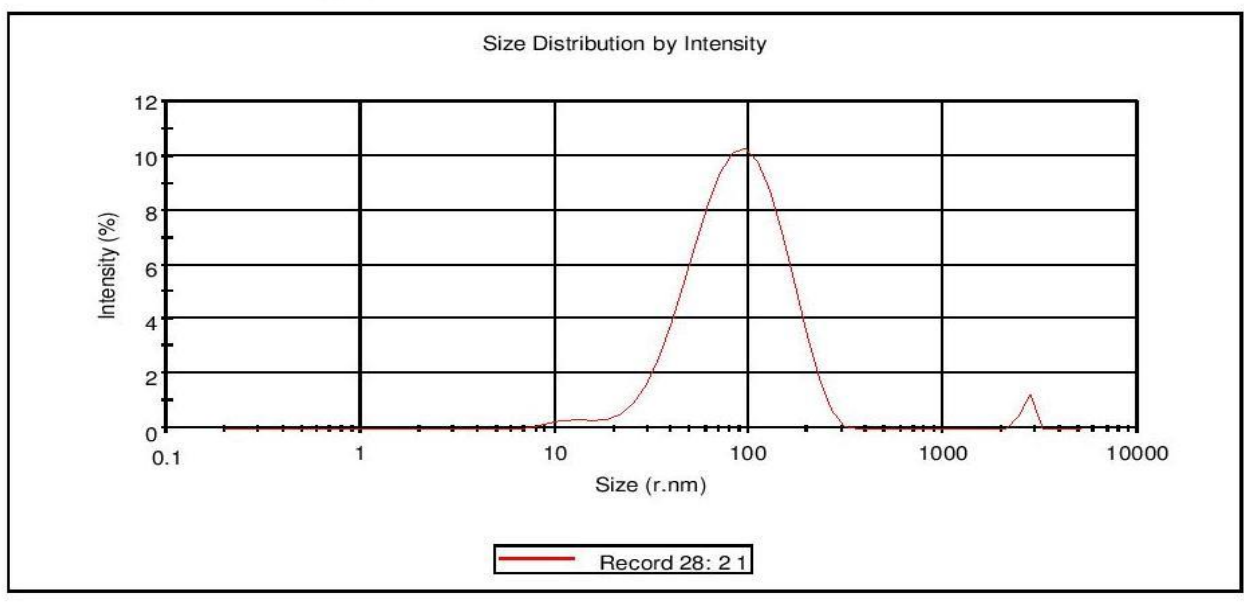

Fig. 12 zeta potential of SLN 6 


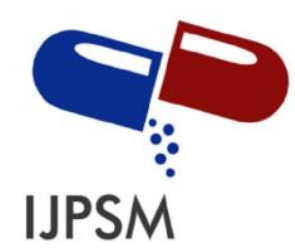

Shivani Khoware et al, Int. Journal of Pharmaceutical Sciences and Medicine (IJPSM),

Vol.6 Issue. 3, March- 2021, pg. 85-109

ISSN: 2519-9889

Impact Factor: 3.426

\section{Comparative in- vitro drug release studies of formulated gel with marketed formulation.}

Drug diffusion study were performing on all formulations F1, F2, F3, F4, F5 and F6 by using of franz diffusion cell. All of the formulation was compared to marketed formulation. The cumulative percent release of SLN loaded gel from F1 to F6 have good penetration power, as compared to marketed gel (ibuprofen). The release of the gel was over the period of $210 \mathrm{~min}$. The result of this studies were signify that administration of SLN loaded gel carrier was safer compared to administration of the free drug or oral formulation.

$\underline{\text { Table-08 Cumulative In-Vitro Release Studies }}$

\begin{tabular}{|l|l|l|l|l|l|l|l|l|}
\hline \multirow{2}{*}{ S.No } & Time (min) & \multicolumn{6}{|l|}{ Cumulative percentage drug release } & \\
\cline { 3 - 9 } & & F1 & F2 & F3 & F4 & F5 & F6 & Ketorol \\
\hline 1 & 0 & 0 & 0 & 0 & 0 & 0 & 0 & 0 \\
\hline 2 & 15 & 4.46 & 6.22 & 7.12 & 7.73 & 7.95 & 8.79 & 7.48 \\
\hline 3 & 30 & 8.93 & 12.37 & 13.90 & 13.79 & 14.96 & 18.76 & 16.24 \\
\hline 4 & 60 & 19.70 & 23.95 & 26.98 & 28.89 & 30.98 & 36.71 & 32.82 \\
\hline 5 & 90 & 30.50 & 35.85 & 39.89 & 42.28 & 44.83 & 52.92 & 49.18 \\
\hline 6 & 120 & 40.43 & 45.69 & 50.56 & 53.97 & 56.96 & 65.83 & 60.84 \\
\hline 7 & 150 & 49.43 & 54.76 & 60.14 & 63.72 & 67.10 & 75.62 & 71.22 \\
\hline 8 & 180 & 58.92 & 62.98 & 69.55 & 73.25 & 75.95 & 83.99 & 79.96 \\
\hline 9 & 210 & 65.86 & 70.85 & 75.93 & 79.96 & 82.92 & 89.95 & 86.49 \\
\hline
\end{tabular}




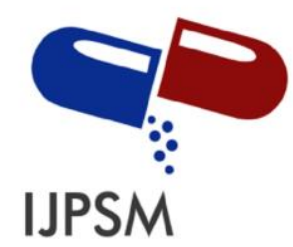

Shivani Khoware et al, Int. Journal of Pharmaceutical Sciences and Medicine (IJPSM),

Vol.6 Issue. 3, March- 2021, pg. 85-109

ISSN: 2519-9889

Impact Factor: $\mathbf{3 . 4 2 6}$

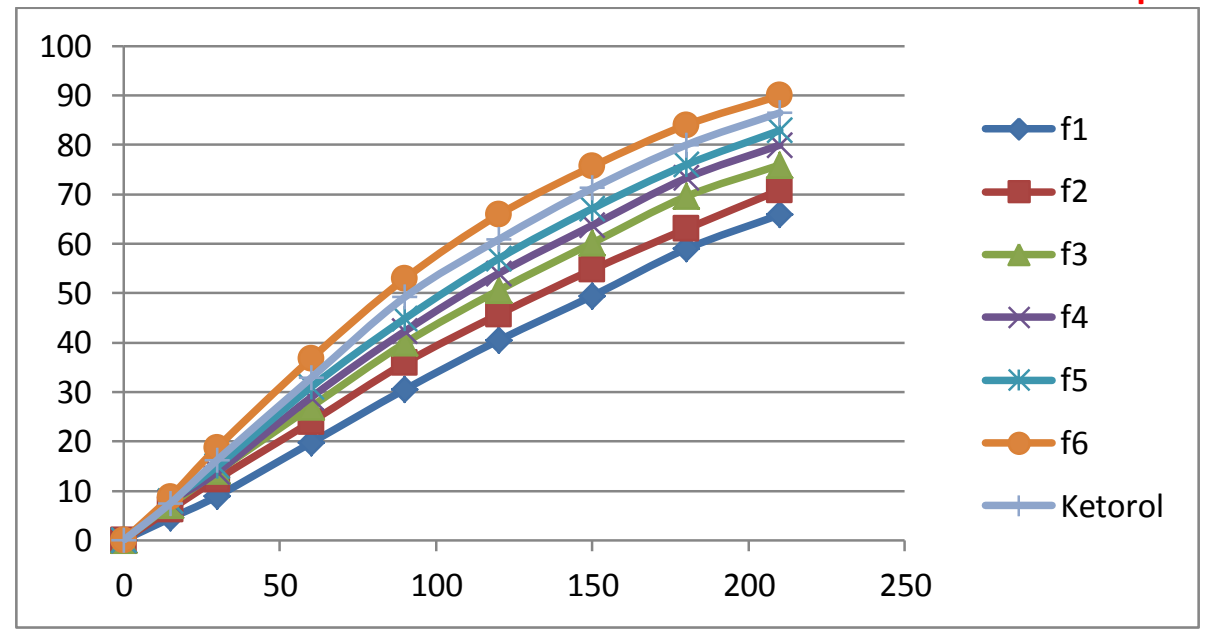

Figure-12 In- Vitro Drug Release

\section{Conclusion}

$>$ Ketorolac tromethamine drug for topical preparation. Ketorolac tromethamine is a NSIDs categories drug that works by reducing hormones that cause inflammation and pain in the body. The aim of these works are prepare solid lipid nanoparticles. Solid lipid nanoparticles is a technique of nanotechnology that's used for increase the biocompatibility, low toxicity of the drug. SLNs are colloidal carrier system in the range of 100-150 $\mathrm{nm}$. Solid lipid nanoparticles were prepared by using melt emulsification and low temperature solidification method. SLNs loaded gel formulation were evaluated for their physical appearance, $\mathrm{pH}$ value, viscosity, spreadability, in- vitro drug release study and stability studies. The $\mathrm{pH}$ value of formulation is normal range in $7.4 \mathrm{pH}$, without reduce of any skin irritation, F3 formulation produce high spradability $3.64 \mathrm{gm}-\mathrm{cm} / \mathrm{sec}$ and the highest viscosity of $3112.23 \mathrm{cps}$. The in vitro release of SLN loaded gel have 89.95. SLNs had been prepared by means of solidification technique and characterize by means of particle measurement, analysis, FTIR spectroscopy, drug entrapment efficiency, $\mathrm{SEM}$, in vitro In vitro release research were performed on Franz diffusion cell the usage of dialysis membrane in phosphate buffer solution of $\mathrm{pH}$ 7.4. The FTIR study indicates no predominant interaction of ketorolac tromethamine with different component ingredients and the Scanning Electron Microscope study revealed that the drug is molecularly dispersion into the lipid. The particle measurement determination confirms the particle distribution in the nanoparticle range (27\% volume to $56 \%$ volume). In vitro drug release using the dialysis membrane as of the prepared SLNs is greatly higher than the pure drug. The stability of the formulation shows the stability of the formulation 


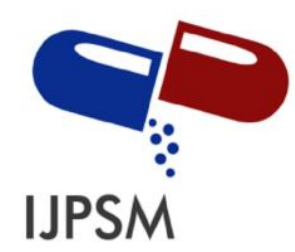

Shivani Khoware et al, Int. Journal of Pharmaceutical Sciences and Medicine (IJPSM), Vol.6 Issue. 3, March- 2021, pg. 85-109

ISSN: 2519-9889

Impact Factor: 3.426

besides changing its performances on storage. Hence formulation of ketorolac tromethamine in SLN, enhances the dissolution price as properly as it will enhance the bioavailability of the drug which ought to the stabilized for the duration of storage.

\section{ACKNOWLEDGEMENT}

I am grateful to Dr. Vimukta Sharma (Principle of, BMCPER Indore) for providing all the research facilities. I am highly thankful to Ms. Amreen Khan for all the support and completion of this work.

\section{AUTHORS CONTRIBUTIONS}

All the author has contributed equally

\section{CONFLICT OF INTERESTS}

The authors declare that they have no conflict of interest

\section{References}

[1]. Parul Raje and Shikha Agrwal. Formulation and evalution of Solid Lipid Nanoparticles based on topical gel of Ibuprofen. Volume 7,2018; 651-666.

[2]. Ekambaram P, Abdul Hasan, Sathali A. Formulation and evalution of Solid Lipid Nanoparticles of ramipril. Journal of young pharmacists volume 3/No 3;2013: 1-216.

[3]. M.R Mozafari, 41-50 (2006).

[4]. Houli Li, Xiaobin Zhao, Yukun Ma and Guangxi Zhai, Ling Bing Li and Hong Xiang, Lou. J. Cont.Release, 133, 238-244 (2009)

[5]. Melike Uner, Gulgun Yener, Int. J. Nanomedicine, 2(3), 289-300 (2007).

[6]. S. Mukherjee, S. Ray and R. S. Thakur, Ind. J. Pharm. Sci., 349-358 (2009).

[7]. Wolfgang Mehnart and Karsten Mader, Adv. Drug. Deliv. Rev., 47, 165-196 (2001)

[8]. Melike Uner, Gulgun Yener, Int. J. Nanomedicine, 2(3), 289-300 (2007).

[9]. Indu Pal Kaur, Rohit Bhandari, Swati Bhandari and Kakkur. J. Cont. Rel., 127, 97-109 (2008).

[10].Antonio J, Almeida and Eliana Souta, adv. Drug Delivery Rev. 59, 478-490 (2007).

[11]. S. P. Vyas and R. K. Khar, Controlled Drug Delivery - Concepts and Advances, First Edition, Vallabh Prakashan (2002) pp. 38-50

[12].Joseph Robinson and Vincent H. L. Lee, Controlled Drug Delivery - Fundamentals and Applications, 2nd Edition, 4-33. 


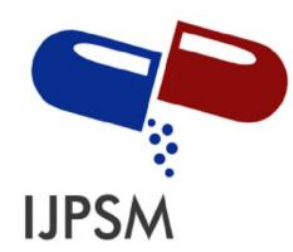

Shivani Khoware et al, Int. Journal of Pharmaceutical Sciences and Medicine (IJPSM), Vol.6 Issue. 3, March- 2021, pg. 85-109

ISSN: 2519-9889

Impact Factor: 3.426

[13].Dong Zhi Hou, Chang Sheng Xie, Kaijn Huang and Chang Hong Zhu, Biomaterials, 24, 1781-1785 (2003)

[14].Rathapon Asasutjarit, Sven - Iver Lorenzen, Sunee Sirivichayakul and Kiat Ruxrungtham, Uracha Ruktanonchi and Garnpimol C. Ritthidej, Pharm. Res., 24(6), 1098 - 1107 (2007).

[15].Suresh Gande, Kopparam Manjunath, Vobalaboina Venkateswarlu and Vemula Satyanarayana, AAPS Pharm. Sci. Tech., 8(1), Article 24 (2007).

[16]. Yung-Chih Kuo and Hung-Hao Chen, Int. J. Pharm., 365, 206-213 (2009).

[17].Speiser P, lipidnanopellets also target system fur Arzneimittel zurr perolen. A nano drug European patent EP 0167; 825: 1990

[18].Domb A.J. lipiosphere for controlled delivery of substance united states patent USS 1888837:1993.

[19].Drake B, Prater CB, Weisenhorn AL, Gould SAC, Albrecht TR, Quate CF et al. imaging creytals polymers and process in water with the AFM science 1989:243:1586-9.

[20].S. Mukherjee, Subhabrata Ray and R. S. Thakur, Pak. J. Pharm. Sci., 22(2), 131-138 (2009)

[21].Ramteke K.H, Joshi S.A, Dhole S.N. solid lipid nanoparticles; journal of pharmacy Issue;2319-4219..

[22]. Verma Surendra and Makkar Deeoika. Solid lipid nanoparticles. A comprehensive review, journal of chemical pharmaceutical research. Issue;0975-7384. Res. 2016,8(8);102-114

[23].Akansha Gard, Depti Singh, Navneet Garud. International current pharmaceutical journal, 2012,1(11) 384-393

[24].Franscesco Lai, Sylvia A. Wissing and Anna M. Fadda, AAPS Pharm. Sci. Tech., 7(1), 2 (2006)

[25].MULLER, R.H.; MADER, K.; GOHLA, S. Solid lipid nanoparticles (SLN) for controlled drug delivery - a review of the state of the art. Eur. J. Pharm. Biopharm., v.50, n.1, p.161-177, 2000.

[26]. Goyal S, Sharma P, Ramchanadani U, Shrivastav SK and Dubey PK. Novel antiinflammatory topical gels. International journal of pharmaceutical and biological archives 2011.2(4);1087-1094

[27].Loveleen Preet Kuar, Tarun Kumar Guleri. Topical gel a recent approach for novel drug delivery. ASIAM journal of biomedical and pharmaceutical science Issue - 2249-622; 2015

[28]. Carter SJ; disperse syatem ins. Cooper and Gunn's Tatorial pharmacy $6^{\text {th }}$ edition. New Delhi CBS publisher and distribution.

[29].Zatz JL,Kushla GP. Gels in Lieberman HA, Riegaz MM And Benker GS. Pharmaceutical dosage form, Dispersion system, $2^{\text {nd }}$ edition new York. Marcel Dekkar 2005;399-421. 


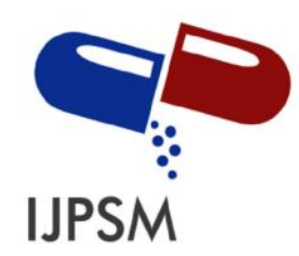

Shivani Khoware et al, Int. Journal of Pharmaceutical Sciences and Medicine (IJPSM), Vol.6 Issue. 3, March- 2021, pg. 85-109

ISSN: 2519-9889

Impact Factor: 3.426

[30]. Rupali Jani, Kaush Jani, Setty C. preparation and evaluation of topical gel valdecoxib. Depti patel, inter, journal pharma. Science, research 2010,2(1) 51-54

[31].Elldem, T., Speiser, P., Hineal, A. (1991). Optimization of spray-dried and congealed lipid microparticles and cha-racterization of their surface morphology by scanning electron microscopy. Pharm Res 8: 47-54

[32].Sjostrom, B., Bergenstahl, B. (1992). Preparation of submicron drug particles in lecithinstabilized $\mathrm{o} / \mathrm{w}$ emulsions I. Model studies of the precipitation of cholesteryl acetate. Int $\mathbf{J}$ Pharm. 88: 53-62

[33].Siekmann, B., Westesen, K. (1994). Thermoanalysis of the recrystallization process of melt-homogenized glyceride nanoparticles. Colloids and Surf B Biointerfaces 3: 159-175.

[34].Muller, R.H., Dobrucki, R., Radomska, A. (1999). Solid lipid nanoparticles as a new formulation with Retinol. Acta Poloniae Pharmaceutica-Drug Research 56(2): 117-120

[35].Cavalli, R., Caputo, O., Gasco, M.R. (2000). Preparation and characterization of solid lipid nanospheres containing paclitaxel. Eur J Pharm Sci 10(4): 305-309.

[36].Elena Ugazia, Roberta Cavalli and M. R. Gasco, Int. J. Pharm., 241, 341-344 (2002)

[37].Agu, R.U., Ugwoke, M.I., Armand, M., Kinget, R., Verbeke, N. (2001). The lung as a route for systemic delivery of therapeutic proteins and peptides. Respir Res 2(4): 198209.

[38].Lee, W.A., Ennis, R.D., Longenecker, J.P., Bengtsson, P. (1994). The bioavailability of intranasal salmon calcitonin in healthy volunteers with and without permeation enhancer. Pharm Res 11(5): 747-750.

[39].Vila, A., Gill, H., McCallion, O., Alonso, M.J. (2004). Trans-port of PLA-PEG particles across the nasal mucosa: effect of particle size and PEG coating density. J Control Release 98(2): 231-244.

[40].Vila, A., Gill, H., McCallion, O., Alonso, M.J. (2004). Trans-port of PLA-PEG particles across the nasal mucosa: effect of particle size and PEG coating density. J Control Release 98(2): 231-244.

[41].Franscesco Lai, Sylvia A. Wissing and Anna M. Fadda, AAPS Pharm. Sci. Tech., 7(1), 2 (2006).

[42].Pallavi V. Pople and Kamalinder K. Singh, AAPS Pharm. Sci. Tech., 7(4), Article 91 (2006).

[43].Ekambaram, P., Abdul Hassan Sathali, A., Priyanka, K. (2012). Solid Lipid Nanoparticles: A Review. Sci Revs Chem Commun 2(1): 80-102

[44].Mishra, H., Mishra, D., Mishra, P.K., Nahar, M., Dubey, V., Jain, D.K. (2010). Evaluation of solid lipid nanoparticles as carriers for delivery of Hepatitis B surface antigen for vaccination using subcutaneous route. J Pharm Pharmaceut Sci 13(4): 495509. 


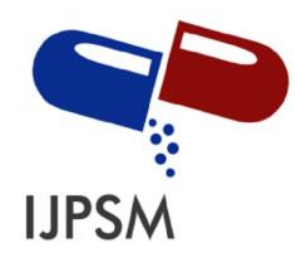

Shivani Khoware et al, Int. Journal of Pharmaceutical Sciences and Medicine (IJPSM), Vol.6 Issue. 3, March- 2021, pg. 85-109

ISSN: 2519-9889

Impact Factor: 3.426

[45].Jenning, V., Gysler, A., Schafer-Korting, M., Gohla, S.H. (2000). Vitamin A loaded solid lipid nanoparticles for topical use: occlusive properties and drug targeting to the upper skin. Eur J Pharm and Biopharm 49(3): 211-218

[46].Friedrich, I., Reichl, S., Müller-Goymann, C.C. (2005). Drug release and permeation studies of nanosuspensions based on solidified reverse micellar solutions (SRMS) Int J Pharm 305(1-2): 167-75.

[47].Rishi Paliwal, Shivani Rai, Bhuvaneshwar Vaidya, Kapil Khatri, Amit K. Goyal, Neeraj Mishra, Abhinav Mehta and Suresh P. Vyas, PhD. Nanomedicine, Nanotechnology, Biology and Medicine 5(2), (2009) pp. 184-191. 